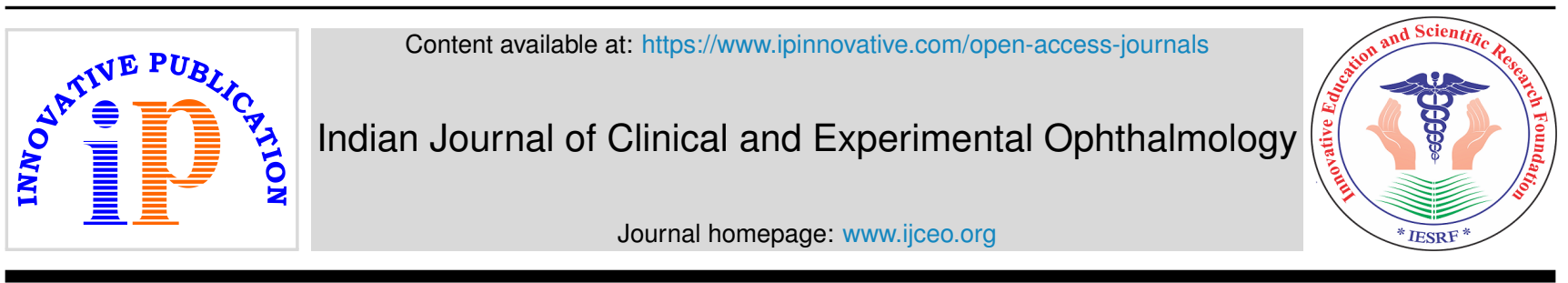

Original Research Article

\title{
Association of serum lipid levels and social factors with diabetic retinopathy in patients with type 2 diabetes mellitus: Study from tertiary care center of Western Maharashtra
}

\author{
Namratha Judith Cardoza, ${ }^{1}$, O K Radhakrishnan ${ }^{1}$, Chaitali Desai ${ }^{1}$, \\ Kavitha Mohankumar ${ }^{1}$, Madhuvanthi Mohan \\ ${ }^{1}$ Dept. of Ophthalmology, D. Y. Patil Medical College, Hospital \& Research Centre, Pune, Maharashtra, India
}

\section{A R T I C L E I N F O}

\section{Article history:}

Received 04-12-2020

Accepted 15-12-2020

Available online 01-04-2021

\section{Keywords:}

Diabetic retinopathy

Education

Locality

Occupation

Serum lipid levels

\begin{abstract}
A B S T R A C T
Purpose: To study the prevalence of dyslipidemia and to find out the correlation between serum lipid levels and social factors like occupation, locality(urban/rural) and education status with diabetic retinopathy in patients with type 2 diabetes mellitus.

Materials and Methods: 200 patients with type 2 diabetes mellitus were segregated into 2 categories:- First category of patients with diabetic retinopathy and second category of patients without diabetic retinopathy. Serum lipid levels of subjects were measured and social history like occupation, locality (urban/rural) and education status was taken. Observations were compared to check association between above factors and diabetic retinopathy.

Results: The prevalence of dyslipidemia was found to be $75.50 \%$. Mean \pm SD of LDL(mg/dL) in patients with diabetic retinopathy was $118.86 \pm 40.58$ which was significantly higher as compared to patients without diabetic retinopathy ( $\mathrm{p}$ value $=0.006$ ). No significant association was seen in the distribution of total cholesterol(mg/dL), HDL (mg/dL), Triglyceride $(\mathrm{mg} / \mathrm{dL}$ ) with diabetic retinopathy (p value $>.05) .10 \%$ of patients with DR worked as clerks while $52 \%$ were homemakers, thus, significant association was seen in the relationship of occupation with the presence of diabetic retinopathy ( $\mathrm{p}$ value $<.05$ ). Diabetic retinopathy was more prevalent among type 2 diabetics living in urban areas $(\mathrm{p}<0.0001) .16 \%$ of patients with DR had studied up to primary school while $28 \%$ of patients with DR had studied up to high school, thus significant association was seen between the education status of the patients and the occurrence of diabetic retinopathy (p value<.05).

Conclusion: Elevated serum LDL levels were found to be a significant risk factor for diabetic retinopathy. Clerks and homemakers were more predisposed to diabetic retinopathy. Subjects who received education up to primary school and high school and subjects living in urban areas had significantly increased rates of diabetic retinopathy.

(C) This is an open access article distributed under the terms of the Creative Commons Attribution License (https://creativecommons.org/licenses/by/4.0/) which permits unrestricted use, distribution, and reproduction in any medium, provided the original author and source are credited.
\end{abstract}

\section{Introduction}

Diabetes mellitus (DM) is a widespread multifactorial disease that imposes a serious burden to our healthcare system. India alone is estimated to have about 69.2 million diabetics and these numbers are predicted to soar as high as 123.5 million by the year 2040..$^{1,2}$

\footnotetext{
* Corresponding author.

E-mail address: namrathacardoza123@gmail.com (N. J. Cardoza).
}

Type 2 diabetics include those individuals who are seen to have insulin resistance (IR) and usually relative deficiency of insulin. Diabetes mellitus leads to microvascular and macrovascular complications. Macrovascular abnormalities include coronary vascular disease, stroke and peripheral vascular disease. The microvascular complications include diabetic retinopathy, diabetic nephropathy and diabetic neuropathy. Chronically elevated blood sugar levels, increase in the reactive oxygen 
species, decrease in the nitric oxides and increase in fatty acids contribute to the chronic vascular complications by changing the vascular response. ${ }^{3}$

A multitude of risk factors have been studied to understand how DR develops and progresses. These include the type of diabetes mellitus and the duration of the disease, gender, age, body-mass index (BMI), glycemic control, hypertension, nephropathy, smoking, pregnancy and serum lipid levels. ${ }^{4,5}$ The importance of serum lipid levels in the development and progression of DR has been assessed worldwide with a lot of variable results. Dyslipidemia, characterized by raised levels of serum total cholesterol (TC), triglycerides (TG), low density lipoprotein cholesterol (LDL-C) and reduced levels of high density lipoprotein cholesterol (HDL-C) have been hypothesized as probable risk factors for DR. Hyperlipidemia is known to cause dysfunction in the endothelium due to reduced nitric oxide and also the breakdown of BRB which leads to lipid exudation and lipoprotein exudation that leads to various changes in DR and leads to diabetic macular edema (DME) formation. ${ }^{6}$ Diabetic macular edema is a common cause of severe vision loss in diabetic patients. ${ }^{7,8}$

Various social factors like occupation, whether the individual lives in a rural or urban locality and education may be associated with diabetic retinopathy. This could be due to changes in lifestyle and diet in these individuals and also due to differences in awareness about the disease and the need for screening. There are also discrepancies in availability of resources and affordability among various social groups.

There have been variations in results and observations from various international studies and there is a scarcity of data from available local literature. Hence, we conducted this study in our tertiary care hospital to explore this interesting relationship between serum lipid levels and other social factors and DR in our local population.

\section{Materials and Methods}

A hospital based observational, cross sectional study was conducted in a tertiary hospital and research centre in Western Maharashtra, from September 2018 to August 2020. 200 patients with type 2 diabetes mellitus, aged 30-70 years were included in the study. Participants were segregated into 2 categories:- (i) category-I of patients with diabetic retinopathy and (ii) category-II of patients without diabetic retinopathy.

Patients with type 1 or indeterminate diabetes mellitus, where OCT was not possible due to hazy media or refusals, any prior ocular treatment, concomitant fundus pathology potentially affecting the macula (e.g arterial/venous occlusions),patients having corneal diseases, inflammatory eye diseases, optic neuropathy and age related macular degeneration, any other ocular pathology that could influence the progression of retinopathy (high myopia, glaucoma, retinitis pigmentosa, other causes of optic atrophy, etc.), any history of radiation to the head or neck region, carotid vascular disease detected by carotid doppler and patients on hemo or /peritoneal dialysis were excluded from the study.

Participant information sheet (PIS) regarding details of study were prepared in English and Marathi language. PIS was given to the participants and they were explained in detail about the study in a language best understood by the patient. Participants were enrolled after getting written informed consent.

A Detailed history from each patient was obtained Following data was collected:

1. Age

2. Sex

3. Locality (urban/rural)

4. Occupation

5. Education status

Vision was assessed using illuminated Snellen's Chart. Anterior segment was evaluated in detail by slit lamp examination and fundus examination was done in a dark room with indirect ophthalmoscope. Fundus was also evaluated by means of direct ophthalmoscopy and slit lamp biomicroscopy with $+90 \mathrm{D}$ lens. Fundus camera was used to obtain a fundus photograph. Participants were segregated into 2 categories. Group-1 included patients with type 2 diabetes mellitus with diabetic retinopathy. Group2 included patients with type 2 diabetes mellitus without diabetic retinopathy. For grading the severity of diabetic retinopathy, Early Treatment Diabetic Retinopathy Study (ETDRS) protocol was followed. For a detailed analysis, the DR group was further divided into patients with NPDR and those with PDR based on the ETDRS protocol.

To measure serum lipid levels, patient was kept fasting for 12 hours (No food or drink, except water). $2 \mathrm{ml}$ of blood was collected from a resting patient using an optimal venopuncture technique in a red vacutainer and serum lipid levels namely serum total cholesterol, HDL cholesterol, LDL cholesterol and triglycerides were measured. Normal range of serum TC is $<200 \mathrm{mg} / \mathrm{dl}$, serum HDL-C is 35 $80 \mathrm{mg} / \mathrm{dl}$ in males and $42-88 \mathrm{mg} / \mathrm{dl}$ in females, serum LDL$\mathrm{C}$ is $<130 \mathrm{mg} / \mathrm{dl}$, serum TG is $40-160 \mathrm{mg} / \mathrm{dl}$. Fasting plasma glucose was measured after an overnight fast $(8$ hours fasting with no food, drink except water). $2 \mathrm{ml}$ of blood was then collected in a grey vacutainer tube containing sodium fluoride as a preservative and fasting blood glucose was measured. Normal levels of fasting blood glucose range between $70-100 \mathrm{mg} / \mathrm{dl}$. Fasting blood glucose level of $126 \mathrm{mg} / \mathrm{dl}$ or above is indicative of diabetes mellitus. To measure $\mathrm{HbA1C}, 2 \mathrm{ml}$ of blood was collected in a lavender vacutainer containing EDTA as a preservative. Normal level of $\mathrm{HbA1C}$ is $4.8-5.9 \%$. HbA1C of $6.5 \%$ or higher is indicative of diabetes mellitus. The above lab tests were 
conducted and results were documented.

All details of participants were kept under strict confidentiality. Data was collected, compiled and tabulated in excel sheet. The categorical variables were presented in number and percentage $(\%)$ form and the continuous variables were presented as mean \pm SD and median. Normality of the data was tested by Kolmogorov-Smirnov test. If the normality was rejected, then the non-parametric test was used.

Statistical tests were applied as follows:

1. Quantitative variables were compared using Independent $\mathrm{t}$ test/Mann-Whitney Test (when the data sets were not normally distributed) between the two groups.

2. Qualitative variables were compared using Chi-Square test/Fisher's Exact test.

A p Value of $<0.05$ was considered to be statistically significant.

The data was analysed using Statistical Package for Social Sciences (SPSS) version 21.0.

\section{Results}

Prevalence of dyslipidemia in our study was $75.50 \%$ ( 151 patients).

Mean \pm SD of $\mathrm{LDL}(\mathrm{mg} / \mathrm{dL})$ in diabetic retinopathy was $118.86 \pm 40.58 \mathrm{mg} / \mathrm{dl}$ and $103.97 \pm 36.34 \mathrm{mg} / \mathrm{dl}$ in patients without diabetic retinopathy .Thus significant association was seen between serum LDL levels and diabetic retinopathy. $(\mathrm{p}=0.006)$

Mean \pm SD of HDL $(\mathrm{mg} / \mathrm{dL})$ in patients with diabetic retinopathy was $38.02 \pm 6.43 \mathrm{mg} / \mathrm{dl}$ and in patients without diabetic retinopathy was $38.34 \pm 8.5 \mathrm{mg} / \mathrm{dl}$ with no significant association between them. $(\mathrm{p}=0.764)$

Mean \pm SD of total cholesterol $(\mathrm{mg} / \mathrm{dL})$ in diabetic retinopathy was $177.76 \pm 56.45 \mathrm{mg} / \mathrm{dl}$ and in patients without diabetic retinopathy was $168.48 \pm 37.55 \mathrm{mg} / \mathrm{dl}$ and no significant association was seen between them. $(\mathrm{p}=0.172)$

Median (IQR) of Triglyceride (mg/dL) in patients with diabetic retinopathy was $135.5(118-208.5) \mathrm{mg} / \mathrm{dl}$ and in patients without diabetic retinopathy was 144.5 (124.5$186) \mathrm{mg} / \mathrm{dl}$ with no significant association between them. $(\mathrm{p}=0.597)$

Patients living in urban areas had more prevalence of diabetic retinopathy in our study. $(\mathrm{p}<0.0001)$

Diabetic retinopathy was more prevalent among clerks and homemakers. $(\mathrm{p}=0.004)$

Patients with primary school and high school education had significant association with diabetic retinopathy. $(\mathrm{p}=0.007)$

\section{Discussion}

In present study, out of 200 patients, 151 patients had dyslipidemia and 76 patients had diabetic retinopathy with dyslipidemia. The prevalence of dyslipidemia was found to be as high as $75.50 \%$ (Table 1). High prevalence of dyslipidemia has also been reported by Parikh et al., ${ }^{9}$ who found the prevalence of dyslipidemia (the parameters used were: triglycerides above $150 \mathrm{mg} / \mathrm{dl}$ or LDL-C equal to or more than $100 \mathrm{mg} / \mathrm{dl}$ or HDL-C less than $40 \mathrm{mg} / \mathrm{dl}$ for males and less than $50 \mathrm{mg} / \mathrm{dl}$ among females) in diabetics $(\mathrm{n}=788)$ to be $97.8 \%$ in females and $85.5 \%$ in males. In another study by Joshi SR et al., $13.9 \%$ subjects were found to have raised total cholesterol, $29.5 \%$ of subjects had elevated triglyceride levels, $72.3 \%$ of subjects had reduced levels of HDL cholesterol, $11.8 \%$ of subjects had raised levels of LDL cholesterol and $79 \%$ of subjects had one of the lipid abnormalities. ${ }^{10}$

In our study, mean $\pm \mathrm{SD}$ of $\mathrm{LDL}(\mathrm{mg} / \mathrm{dL})$ in patients with diabetic retinopathy was $118.86 \pm 40.58$ which was significantly higher as compared to patients without diabetic retinopathy (Table 2) indicating a significant association of $\mathrm{LDL}(\mathrm{mg} / \mathrm{dL})$ with diabetic retinopathy. ( $\mathrm{p}$ value=0.006). This can be corroborated with the 1996, ETDRS report no. 22, which evaluated the relationship between serum lipid levels and retinal hard exudates in 2709 patients with diabetic retinopathy. At baseline, patients who were found to have elevated serum total cholesterol or elevated serum low-density lipoprotein cholesterol (LDL-C) levels were more likely to have retinal hard exudate. ${ }^{11}$

In our study, no significant association was seen in the distribution of total cholesterol (mg/dL), HDL(mg/dL), Triglyceride $(\mathrm{mg} / \mathrm{dL})$ with diabetic retinopathy $(\mathrm{p}$ value $>.05$ )(Table 2)

Similar results were seen in a meta-analysis of 7 studies conducted by Yue Zhou et al., where obvious differences in TG, TC and HDL-C levels between patients with diabetic retinopathy and those without diabetic retinopathy were not found. However, slightly higher LDL-C levels were observed in the DR cases and in their study, Fenofibrate was proven to be beneficial in patients with DR and dyslipidemia. ${ }^{12}$ In a study by Idiculla $\mathrm{J}$ et al., ${ }^{13}$ retinal hard exudate formation was found to have a positive statistical correlation with the presence of dyslipidemia $(p=0.02)$, increased levels of total cholesterol $(\mathrm{p}=0.002)$ and also LDL levels $(\mathrm{p}=0.001)$.

In our study, significant association was found in the distribution of locality with diabetic retinopathy $(p$ value<.05). $88 \%$ of patients with diabetic retinopathy (Table 3) resided in urban areas. This was significantly higher as compared to patients without diabetic retinopathy (52\% resided in urban areas). These findings were similar to a study conducted in Chennai, India, where DR prevalence was observed to be $18 \%$ in urban areas. ${ }^{14}$ compared to $10.8 \%$ in rural areas. ${ }^{15}$ This could be due to differences in the diet in urban areas and patients succumbing to diabetes related complications in rural areas due to difficulty in accessing better healthcare facilities. However, in a study 
Table 1: Prevalence of dyslipidemia of study subjects

\begin{tabular}{lcc}
\hline Dyslipidemia & Frequency & Percentage \\
No & 49 & $24.50 \%$ \\
Yes & 151 & $75.50 \%$ \\
Total & 200 & $100.00 \%$ \\
\hline
\end{tabular}

Table 2: Association of lipid profile with diabetic retinopathy

\begin{tabular}{|c|c|c|c|c|c|}
\hline Lipid profile & $\begin{array}{c}\text { Diabetic } \\
\text { retinopathy }(n=100)\end{array}$ & $\begin{array}{c}\text { No diabetic } \\
\text { retinopathy }(n=100)\end{array}$ & Total & $P$ value & Test performed \\
\hline \multicolumn{6}{|c|}{ Total cholesterol (mg/dL) } \\
\hline Normal & $69(69 \%)$ & $79(79 \%)$ & $148(74 \%)$ & \multirow{2}{*}{0.107} & \multirow{2}{*}{$\begin{array}{l}\text { Chi square } \\
\text { test, } 2.599\end{array}$} \\
\hline Deranged & $31(31 \%)$ & $21(21 \%)$ & $52(26 \%)$ & & \\
\hline Mean \pm SD & $177.76 \pm 56.45$ & $168.48 \pm 37.55$ & $173.12 \pm 48.05$ & & \\
\hline Median(IQR) & $169(132-210)$ & $166(134.25-190)$ & $167(132-201)$ & 0.172 & $\mathrm{t}$ test $; 1.369$ \\
\hline Range & $108-372$ & $91-269$ & $91-372$ & & \\
\hline \multicolumn{6}{|l|}{ HDL(mg/dL) } \\
\hline Normal & $46(46 \%)$ & $52(52 \%)$ & $98(49 \%)$ & \multirow{2}{*}{0.396} & \multirow{2}{*}{$\begin{array}{l}\text { Chi square } \\
\text { test, } 0.72\end{array}$} \\
\hline Deranged & $54(54 \%)$ & $48(48 \%)$ & $102(51 \%)$ & & \\
\hline Mean \pm SD & $38.02 \pm 6.43$ & $38.34 \pm 8.5$ & $38.18 \pm 7.52$ & \multirow{3}{*}{0.764} & \multirow{3}{*}{ t test; 0.3} \\
\hline Median(IQR) & $38(35-42)$ & $38(34.75-42)$ & $38(35-42)$ & & \\
\hline Range & $22-53$ & $21-64$ & $21-64$ & & \\
\hline \multicolumn{6}{|l|}{ LDL(mg/dL) } \\
\hline Normal & $59(59 \%)$ & $78(78 \%)$ & $137(68.50 \%)$ & \multirow{2}{*}{0.004} & \multirow{2}{*}{$\begin{array}{l}\text { Chi square } \\
\text { test, } 8.365\end{array}$} \\
\hline Deranged & $41(41 \%)$ & $22(22 \%)$ & $63(31.50 \%)$ & & \\
\hline Mean $\pm \mathrm{SD}$ & $118.86 \pm 40.58$ & $103.97 \pm 36.34$ & $111.42 \pm 39.14$ & \multirow{3}{*}{0.006} & \multirow{3}{*}{$\mathrm{t}$ test; 2.733} \\
\hline Median(IQR) & $118.5(82-141)$ & $100(76-125.25)$ & 102(80.75-138) & & \\
\hline Range & $56-240$ & $49-190$ & $49-240$ & & \\
\hline \multicolumn{6}{|c|}{ Triglyceride(mg/dL) } \\
\hline Normal & $71(71 \%)$ & $60(60 \%)$ & $131(65.50 \%)$ & \multirow{2}{*}{0.102} & \multirow{2}{*}{$\begin{array}{l}\text { Chi square } \\
\text { test, } 2.677\end{array}$} \\
\hline Deranged & $29(29 \%)$ & $40(40 \%)$ & $69(34.50 \%)$ & & \\
\hline Mean \pm SD & $161.02 \pm 81.55$ & $152.15 \pm 48.6$ & $156.58 \pm 67.1$ & \multirow{3}{*}{0.597} & \multirow{3}{*}{$\begin{array}{c}\text { Mann Whitney } \\
\text { test; } 4784\end{array}$} \\
\hline Median(IQR) & $135.5(118-208.5)$ & 144.5 (124.5-186) & $140(119.5-189)$ & & \\
\hline Range & $42-431$ & $67-260$ & $42-431$ & & \\
\hline
\end{tabular}

Table 3: Association of locality with diabetic retinopathy

\begin{tabular}{lccccc}
\hline Locality & $\begin{array}{c}\text { Diabetic } \\
\text { retinopathy(n=100) }\end{array}$ & $\begin{array}{c}\text { No diabetic } \\
\text { retinopathy(n=100) }\end{array}$ & Total & P value & Test performed \\
Rural & $12(12 \%)$ & $48(48 \%)$ & $60(30 \%)$ & & Chi square \\
Urban & $88(88 \%)$ & $52(52 \%)$ & $140(70 \%)$ & $<.0001$ & test, 30.857 \\
Total & $100(100 \%)$ & $100(100 \%)$ & $200(100 \%)$ & & \\
\hline
\end{tabular}

Table 4: Association of occupation with diabetic retinopathy

\begin{tabular}{|c|c|c|c|c|c|}
\hline Occupation & $\begin{array}{c}\text { Diabetic } \\
\text { retinopathy }(n=100)\end{array}$ & $\begin{array}{c}\text { No diabetic } \\
\text { retinopathy }(n=100)\end{array}$ & Total & $P$ value & Test performed \\
\hline Astrologer & $0(0 \%)$ & $1(1 \%)$ & $1(0.50 \%)$ & & \\
\hline Clerk & $10(10 \%)$ & $4(4 \%)$ & $14(7 \%)$ & & \\
\hline Electrician & $1(1 \%)$ & $0(0 \%)$ & $1(0.50 \%)$ & & \\
\hline Farmer & $13(13 \%)$ & $32(32 \%)$ & $45(22.50 \%)$ & & \\
\hline Homemaker & $52(52 \%)$ & $34(34 \%)$ & $86(43 \%)$ & & \\
\hline Plumber & $1(1 \%)$ & $4(4 \%)$ & $5(2.50 \%)$ & & \\
\hline Retired clerk & $3(3 \%)$ & $0(0 \%)$ & $3(1.50 \%)$ & 0.004 & Fisher Exact test \\
\hline Retired mechanic & $1(1 \%)$ & $0(0 \%)$ & $1(0.50 \%)$ & & \\
\hline Retired welder & $2(2 \%)$ & $6(6 \%)$ & $8(4 \%)$ & & \\
\hline Shop owner & $8(8 \%)$ & $9(9 \%)$ & $17(8.50 \%)$ & & \\
\hline Teacher & $6(6 \%)$ & $7(7 \%)$ & $13(6.50 \%)$ & & \\
\hline Vendor & $3(3 \%)$ & $3(3 \%)$ & $6(3 \%)$ & & \\
\hline Total & $100(100 \%)$ & $100(100 \%)$ & $200(100 \%)$ & & \\
\hline
\end{tabular}


Table 5: Association of education status with diabetic retinopathy

\begin{tabular}{|c|c|c|c|c|c|}
\hline Education status & $\begin{array}{c}\text { Diabetic } \\
\text { retinopathy }(n=100)\end{array}$ & $\begin{array}{c}\text { No diabetic } \\
\text { retinopathy }(n=100)\end{array}$ & Total & P value & Test performed \\
\hline $\begin{array}{l}\text { No formal } \\
\text { education }\end{array}$ & $20(20 \%)$ & $43(43 \%)$ & $63(31.50 \%)$ & \multirow{6}{*}{0.007} & \multirow{6}{*}{$\begin{array}{l}\text { Chi square } \\
\text { test, } 14.201\end{array}$} \\
\hline Primary school & $16(16 \%)$ & $9(9 \%)$ & $25(12.50 \%)$ & & \\
\hline Middle school & $20(20 \%)$ & $20(20 \%)$ & $40(20 \%)$ & & \\
\hline High school & $28(28 \%)$ & $16(16 \%)$ & $44(22 \%)$ & & \\
\hline College & $16(16 \%)$ & $12(12 \%)$ & $28(14 \%)$ & & \\
\hline Total & $100(100 \%)$ & $100(100 \%)$ & $200(100 \%)$ & & \\
\hline
\end{tabular}

conducted in China, DR prevalence in urban areas $(18.1 \%)$ was much lower than in rural areas $(29.1-43.1 \%) .{ }^{16,17}$

Significant association was seen in the relationship of occupation with the presence of diabetic retinopathy in our study ( $p$ value<.05). $10 \%$ of patients with DR worked as clerks while $52 \%$ were homemakers (Table 4). This was significantly higher as compared to patients without diabetic retinopathy $(4 \%, 34 \%$ respectively). $32 \%$ of patients without diabetic retinopathy were farmers compared to $13 \%$ of patients with diabetic retinopathy.

One prior study found that people working in sales, people engaged in manual work and unemployed individuals or housewives were screened less frequently for DR. However, the frequency of screening for DN was not affected by the occupation of the patient. ${ }^{18}$

In our study, significant association was seen between the education status of the patients and the occurrence of diabetic retinopathy ( $\mathrm{p}$ value<.05). $16 \%$ of patients with DR had studied up to primary school while $28 \%$ of patients with DR had studied up/to high school(Table 5). This was significantly higher as compared to patients without diabetic retinopathy ( $9 \%, 16 \%$ respectively). On the other hand, $43 \%$ of patients without DR had no formal education which was significantly higher than patients with diabetic retinopathy (20\%). Many previous studies ${ }^{18-21}$ have confirmed that lower educational levels reduce frequency of DN and DR screening which could be due to lack of awareness and inability to understand the seriousness and the consequences of the complications of diabetes and due to lack of support and resources.

\section{Conclusion}

Various systemic risk factors have been studied and linked to diabetic retinopathy. Serum lipid levels seem to play a salient role in the progression of diabetic retinopathy. Significant association was seen in the distribution of LDL cholesterol in patients with diabetic retinopathy.

Clerks and homemakers were more predisposed to diabetic retinopathy. Subjects who were educated up to primary school and high school and subjects living in urban areas had significantly increased rates of diabetic retinopathy.

\section{Source of Funding}

None.

\section{Conflict of Interest}

The authors declare that there is no conflict of interest

\section{References}

1. International Diabetes Federation; 2015. 7th ed.

2. Kiran PU, Srinivas B. Study of glycated haemoglobin, lipid profile and uric acid levels in diabetic retinopathy. Sch J App Med Sci. 2015;3(7A):2480-4.

3. Maurya RP. Diabetic retinopathy :My brief synopsis. Ind J Clin Exp Ophthalmol. 2015;1(4):189-90.

4. Kanski JJ, Bowling B. Clinical Ophthalmology - A Systematic Approach. 7th ed. London: Elsevier; 2011.

5. Javadi MA, Katibeh M, Rafati N, HDehghan M, Zayeri F, Yaseri $\mathrm{M}$, et al. Prevalence of diabetic retinopathy in Tehran province: a population-based study. BMC Ophthalmology. 2009;9(1):12.

6. Klein BE, Moss SE, Klein R, Surawicz TS. The Wisconsin Epidemiologic Study of Diabetic Retinopathy. XIII. Relationship of serum cholesterol to retinopathy and hard exudate. Ophthalmology. 1991;98(8):1261-5.

7. Maurya RP. Dabetic macular edema: An overview. Indian J Clin Exp Ophthalmol. 2019;5(1):1-2.

8. Gupta SK, Yadav I, Deshmukh S, Maurya RP, Singh VP. Predictors of visual response to intravitreal Bvacizumab for treatment of diabetic macular edema. Ind J Clin Ophthalmol. 2015;1(1):35-40.

9. Parikh RM, Joshi SR, Menon PS, Shah NS. Prevalence and pattern of diabetic dyslipidemia in Indian type 2 diabetic patients. Diabetes Metab Syndr: Clin Res Rev. 2010;4(1):10-2.

10. Joshi SR, Anjana RM, Deepa M. Prevalence of dyslipidemia in urban and rural India: the ICMR-INDIAB study. PLoS One. 2009;9(5):e96808.

11. Chew EY, Klein ML, Ferris FL, Remaley NA, Murphy RP, Chantry $\mathrm{K}$, et al. Association of elevated serum lipid levels with retinal hard exudate in diabetic retinopathy. Early Treat DiabetRetinopathy Study (ETDRS) Rep. 1996;22(9):1079-84.

12. Zhou Y, Wang C, Shi K, Yin X. Relationship between dyslipidemia and diabetic retinopathy: A systematic review and meta-analysis. Medicine (Baltimore). 2018;97(36):12283.

13. Idiculla J, Nithyanandam S, Joseph M, Mohan VA, Vasu U, Sadiq M, et al. Serum lipids and diabetic retinopathy: A cross-sectional study. Indian J Endocrinol Metab. 2012;16(2):492-4.

14. Gadkari SS, Maskati QB, Nayak BK. Prevalence of diabetic retinopathy in India: The All India Ophthalmological Society Diabetic Retinopathy Eye Screening Study. Indian J Ophthalmol. 2014;64(1):38-44.

15. Raman R, Ganesan S, Pal SS, Kulothungan V, Sharma T. Prevalence and risk factors for diabetic retinopathy in rural India. Sankara Nethralaya Diabetic Retinopathy Epidemiology and Molecular 
Genetic Study III (SN-DREAMS III), report no 2. BMJ Open Diabetes Res Care. 2014;2(1):e000005.

16. Liu L, Wu X, Liu L, Geng J, Yuan Z, Shan Z. Prevalence of diabetic retinopathy in mainland China: a meta-analysis. PLoS One. 2012;7(9):45264.

17. Wang FH, Liang YB, Zhang F, Wang JJ, Wei WB, Tao QS, et al Prevalence of diabetic retinopathy in rural China: the Handan Eye Study. Ophthalmology. 2009;116(3):461-8.

18. Byun SH, Ma SH, Jun JK, Jung KW, Park B. Screening for diabetic retinopathy and nephropathy in patients with diabetes: a nationwide survey in Korea. PLoS One. 2013;8(5):62991.

19. Rim TH, Byun IH, Kim HS, Lee SY, Yoon JS. Factors associated with diabetic retinopathy and nephropathy screening in Korea: the Third and Fourth Korea National Health and Nutrition Examination Survey (KNHANES III and IV). J Korean Med Sci. 2013;28(6):814-20.

20. Ko KD, Kim BH, Park SM, Oh SN, Um CS, Shin DW. What are patient factors associated with the quality of diabetes care?: results from the Korean National Health and Nutrition Examination Survey. BMC Public Health. 2012;12:689.

21. Do YK, Eggleston KN. Educational disparities in quality of diabetes care in a universal health insurance system: evidence from the 2005 Korea National Health and Nutrition Examination Survey. Int J Qual Health Care. 2011;23(4):397-404.

\section{Author biography}

Namratha Judith Cardoza, Junior Resident

O K Radhakrishnan, Professor

Chaitali Desai, Junior Resident

Kavitha Mohankumar, Junior Resident

Madhuvanthi Mohan, Junior Resident

Cite this article: Cardoza NJ, Radhakrishnan OK, Desai C,

Mohankumar K, Mohan M. Association of serum lipid levels and social factors with diabetic retinopathy in patients with type 2 diabetes

mellitus: Study from tertiary care center of Western Maharashtra. Indian J Clin Exp Ophthalmol 2021;7(1):218-223. 